credulity has so monstrously puerile a belief been exploited. To deny the existence of disease, to deny the reality of pain, to disregard all physical measures of relief, to sweep away in a spiritual ecstasy the accumulated wisdom of centuries in a retarn to Oriental mysticism-these, indeed, expressed a revolt from the materialism of the latter half of the nineteenth century at once weird, perhaps not unexpected, and, to a student of human nature, just a bit comic. One cannot but smile to think that this has happened at the very time when the Goddess of Reason was priding herself on the brilliancy of the accomplishments of her devotees ! It is, indeed, a salutary lesson in humility, and serves to remind us that our deliciously credulous human nature is still plastic and receptive. To some a sign of decadence, to me the growth of Christian Science and of Mormonism are among the hopefal indications that we are in the childhood of the race. Only in the welter of a new world, untrammelled by a past, and by regard for authority, among a keen people too much absorbed in business to work out for themselves any mental salvation could such a chaotic mass of rubbish have had any measure of successful acceptance. And, as I said, the panishment fits the crime. For generations the people of the United States have indulged in an orgie of drugging. Between polypharmacy in the profession, and quack medicines, the American body had become saturated ad nauseam, and here indeed was a boon even greater than homoeopathy! No wonder the American spirit, unquiet in a drug.soaked body, rose with joy at a new Evangel. In every county there were dyspeptics and neurasthenics in sufficient numbers to demonstrate the efficacy of the new gospel! But the real secret of the growth of Christian Science does not lie in the refusal of physical measures of relief or the efficacy of prayer, but in offering to people a way of life, a new Epicureanism which promises to free the soul (and body) from fear, care, and unrest; and its real lever is the optimism which discounts the worries of the daily round. It has done the profession good in awakening an interest in a too much neglected section of rational therapeutics. The tragic side of the story lies in the valuable lives sacrificed to the fanatical ignorance of so.called healers. The miracles of Christian Science are the faith cures which we all know so well. They are exclusively in the realm of functional disorders. I have not met with any case of organic disease permanently cured. I know of reputed cures of locomotor ataxia ; two of these patients still take opium for the lightning pains.

4. And, lastly, there has arisen in the United States a form of faith healing known as the "Emmanuel Charch movement," which originated in Boston with the Rev. Dr. Worcester, an able and distinguished clergyman of the Episcopal Church, who had had a good training in psychology under Fechner at Leipzig. Curiously the idea arose out of the success which had attended the organization among the members of his church of classes for the home treatment of tuberculosis by my friend and former pupil, Dr. J. H. Pratt. It was suggested that the Church might undertake the treatment of nervous troubles by mental and spiritasl agencies. The method is as follows (I quote for brevity from Powell's The Emmanuel Movement in a New England Town, 1909):

The Emmanuel movement in Boston makes use of both the social uplift and the individual direction. There is a class for the prevention of functional ailments as well as a clinic for their cure. Any Wednesday evening from October until May you wil flnd, if you drop in at Emmanuel Church-one of the most besutiful church interiors in the land, well filled with worshippers, to the astonishment of those who think the mid-week service a spent force in organized religions life. A restful prelude on the organ allures the soul to worship. Without the sid of any choir several familiar hymns are sung by everybody who can sing and many who can not. A Bible lesson is rody Apostis' Crad who can hou Apostes Cor prayers in special cases are gathered up into one prayerful effort made without the help of any book. One Wednesday evening another some expert in neurology or psychology. The theme in uther some expert in neurology or psychology. The theme is usually one of practical significance, like hurry, worry, fear, or grief, and the healing Christ is made real in consequence to many an unhappy heart. Though the mass effect of the service, which is always followed by a purely social hour in the adjoining parish house, is prophylactic, it is not at all uncommon for insomnia, neuralgis, and kindred ills to disappear in the seli-forgetfulness of such an evening.

But it is in the clinic, conducted every day by ope or other of the two head workers assisted by eleven helpers, that the treatment is direct and definite. Every applicant must first submit to diagnosis. If organic trouble is disclosed, he is not accepted as a patient. If the disezse appears to be simply functional, the applicant is registered for treatment and passed on into the Rector's study. There he finds himself in an environment in which the very appointments of the room con duce to the disclosure of every fact, physical, mental, social, moral, spiritual, which bear in any physical, mental, social, moral, spiritual, which bears in any way upon the situation. To the is addod the confdonco which tho contossional inspires. Al the conditions are for many a new patient immediately supplied lead by rapid stages to complete recovery

Where more is needed than the full self-revelation-in itself curative-and the prayer and godly counsel which succeed it, the patient is next invited to be seated in a reclining chair, taught to relax all his muscles, calmed by soothing words and in a state of physical relaxation and mental quie the unwholesome thoughts and the untoward symptoms are dislodged from his consciousness, and in their place are sown the seeds of more health-giving thoughts and ontbalks. men ment, they frequently lose interest in the ailments which were once their torment and cease to think at all about them,
physical health becomes a casual by-product of the spiritual physical health becomes a casual by-product of the spiritual uplift, and the sometime patient, well once more, one day goes seen God face to face, and my life is preserved."

But the patient has his share in applying the treatment. The cure is never permanent without his complete and constant co-operation.

As the Rev. Lyman Powell says, in the excellent book from which I have taken this extract, "The only magic known in the Emmanuel movement is the magic of a mind surcharged with faith, and operative within bounds set by the scientific doctor." Here, again, the success will depend in the individual character of the man conducting the move. ment. The class organization, the association with church services, and the confidence inspired by the co-operation of pastor and doctor have been favouring features. Only in existence for a few years, it is impossible to say what the future has in store, but it is an honest attempt to bring back that angelical conjunction, as Cotton Mather calls it, of physic with divinity.

Briefly stated, this is the status of the faith problem in medicine to-day. Others will analyse its workings, the relation to suggestion, to the subconscious self, etc. Not a pyschologist but an ordinary clinical physician concerned in making strong the weak in mind and body, the whole subject is of intense interest to me. I feel that our attitude as a profession should not be hostile, and we must scan gently our brother man and sister woman who may be carried away in the winds of new doctrine. A group of active, earnest, capable young men are at work on the problem, which is of their generation and for them to solve. The angel of Bethesda is at the pool-it behoves us to jump in !

\section{CONSIDERATIONS ON THE OCCULT.*} BY

T. CLAYE SHAW, M.D., F.R.C.P., FMERITUS LECTURER ON PSYCHOLOGIOAL MEDICINE, ST. BARTHOLOMEW'S HOSPITAL.

Gentlemen, - I am introdacing to you a subject which is at present fall of mystery, because the time is probably not far distant when we shall be much enlightened on the nature and application of these occult processes, and as you will possibly be in active practice during the new eventful years, I beg permission to place before you some ideas which strike me as being relevant to the subject, in the hope that your attention may be drawn to it with the view of assisting, as opportunity offers, the exploitation of phenomena the nature of which it is impossible to predicate at the present.

The Vibration Theory.

Through the vibrations of ether we become conscious of what is going on outside us, at any rate in the regions of sight and hearing, and it is to be assumed that in some way or other these vibrations of ether are transformed into a mulecular conduction along the nerve paths to the central cells themselves, so that a cell which is energizing is a cell in motion in a definite way, and as long as this

* A lecture delivered at the London Polyclinic. 
motion lasts so long does consciousness or activity continue. Kingdon Clifford recognized this, and he remarked that:

The vibratory motion of solids, which is really a molecular disturbance, is absorbed by being transformed into other kind of molecular motion, and so may finally be transmitted to the ether. (Lectures, i, 246.)

The importance of what Clifford wrote is manifest, for it postulates not only that external vibrations may be transmitted to the internal nervous mechanism, but that the reverse process may take place, namely, that central nervous action (for example, as in the process of active attention) may be transmitted outwards to the ether, where, of course, it ought to be capable of demonstration. If this is true it would account for telepathic influence, a possibility asserted but not yet proved. We may understand how it would be possible that internal vibration which is communicated to an external medium might, if meeting with vibrations of a similar quality, serve to reinforce the latter so as to evoke a reciprocal effect (consciousness) in the centre whence the reinforced vibrations emanated. Examine this process a little more closely. How would it occur? It would mean that in the respective spheres, say, of sight, audition, and sound (words), central impulses were communicated to the external ether, and that these must correspond with the internal process. If an image is formed on the retina it sets up certain internal processes which eventuate in what we call the perception and the consciousness of that image.

Now take the reverse process. Is it possible so to revivify (say by active attention) those internal processes that the image shall again be produced on the retina, and even further, so as to act upon external media?

There are psychologists who hint at their belief in this reverse excitation-for example, Professor Sally. If this is true of one sense, it must be true of the others, and the theory may be extended to include the whole body.

It may not be given to every one to be able to re.excite central processes so that they may How with such intensity in the reverse direction, but there are persons of such intense concentration that they do seem capable of re-exciting dormant tracts. I knew an anatomist who said that he could so realize a dissection that when thinking of it he could actually see the parts before bim as if they were really present, and it is common knowledge that painters can carry away an impression of a landscape and reproduce it in detail at their leisure, and this not merely by the memory that there were certain details of form and colour here and there, but by an actual revivifying of the first impression.

That the body itself irradiates into space is more than probable, though we are jgnorant of all the conditions under which this occurs. Some persons of high sensibility can detect the presence of a living object in a dark room without the previous knowledge that there was any occupant, and this is intelligible when we consider that the body being a warm living thing, there must be physical emanations, alterations of air currents, and so forth. But there must be other conditions of radiation which we may conceive must exist though we cannot prove them. For instance, a well.known actor declared to me the other day that when resident in some parts of America he was in a state of electric tension, that by simply rubbing his feet on the carpet he became so charged with electricity that on raising his finger to another person there was an explosion of a small electric spark, and that he could light the gas by approaching his finger to a jet when the tap was turned on, just in the same way as happens to any one who is charged by a high-tension current of electricity. There is, probably, no such a sensitive receptor as certain developments of the human body, and when one asserts that be has feeling of a certain kind, or that he can see or hear certain things which to other less receptive organisms are not apparent, we should be able to allow that the condition is quite possible and that the recipient of the impressions is a living scientific proof of it. And yet we do hesitate to accord our bolief because we ourselves may not be able to perceive what is asserted, nor are, perhaps, capable of being made to appreciate it owing to our own defective mechanisms, and so we at once not only think of decep tion but openly proclaim it. Why? Just because it canno be proved and brought home to universal cognition. There are people who feel uneasy and even ill, depressed and sick, in certain atmospheric conditions when others are in no way affected-then a thunderstorm comes on, and the victims of the unseen and unsuspected influence are restored to normal equilibrium. That was a distinct vitophysical experiment demonstrated by a certain quality of organism alone. An individual in such a state that be can light the gas by just presenting his finger must be irradiating force in a way that would never have been suspected but for the coarse realization of objective experiment.

In the personality of some individuals the indescribable impression of latent force becomes objective; it is beld probable that we are in this instance affected, not by history, tradition, or mere external peculiarity in bulk, form, or manner, so much as by an actual emanation of force in some shape of which our mental reception is really the exponent, the physical prool by experiment. But no such emanation has yet been proved.

Still more evident is the action of the spoken word. Here there is no doubt about the fact of vibrations com. municated, and when of a certain intensity, received upon a medinm, and, we mast think, not only received but received by the listener in the same way as they are emitted by the speaker. If I stand at a distance-say, twenty yards-from the person whom I am addressing, the latter hears what I say if I only speak loud enough. Now, it ought to be possible to trace the progress. of the vibrations through the space intervening, for, no doubt, the physical movement does exist. but 80 far it is not possible to show what happens. And if, as we must conceive, there are different degees of sensitiveness or receptivity in individuals, it follows that the spoken word may be of the lowest intensiveness, and therefore inandible for some though perceptible by others. Consider wireless telegraphy. That an alteration of the air-medium between the primary apparatus and the receiving station exists there is no possible doubt, because by suitable means it is easy to interrupt-as it were to steal-the message; but there is no other evidence of this active state, though motion of some kind is constantly going on in it. The telephone is different-it is, for the time being, a part of the body, there is a visible continuity; but what we want is to ascertain the process going on in non perceived media. As a rule, women are more sensitive to sensstional impressions than men, and though I do not profess to know the conditions under which intracommunication exists in the case of the Zancigs, I can quite anderstand that if the positions were reversed, and if he were made the receiver instead of the lady, the exhibition might not be possible.

The Psycho.Physical Society is at present little more than a record of personal experiences, and because it presents nothing but assertions without physical and demonstrable proof people are inclined to scoff at its lucubra. tions, but in common fairness it ought to be allowed that if, during séances, or in the giving of expositions, or even in the mere narration of experiences, some condition of nervous excitement is produced (called by many people hysteria, nervousness, etc.), this very condition of excitement or tension is favourable to the reception of impres. sions which would be otherwise imperceptible. That charlatans exist in this special direction must be because of the want of true scientific interpretation, bat that does not invalidate the probability of trath being at the bottom of it. There are charlatans in medicine and surgery, especially in the departments where our knowledge is most defective-as we know to our cost-for is not public gullibility the quantitative test of our fallibility?

To my own knowledge the following occurred

A man went down to a river to fish and was not seen again; the river was diligently searched for many days but no trace of him was found. Then a keeper's daughter had a night vision-a dream, if you like-that she saw the body in a certain pool which she named; and there, as a fact, the body was found.

Of course, the girl knew the river, had heard of all that had been done in the way of searching, knew of the reward for the finding of the body, and doubtless bad thought much upon a subject which caused intense local excitement; but may not that very excitement have ren. dered her susceptible to actual movements which must have occurred and which, as it were, accidentally, perhaps, 
came within the sphere of her cognition? No, you will say, it was a mere coincidence, or a judgement founded on reasoning that this particular pool had, perhaps, not been searched. Well, it may be so, but on the other hand, there was no certainty that the man was in the river at all. Daring his act of going to the pool and of falling in there nust have been a great disturbance of medial agencies which only awaited the necessary receptor for their recognition.

A man with good eyesight might have seen the occurrence a quarter of a mile off; a hawk with better eyesight might have seen it at $t$ wice or three times the distance. Why may not this girl have been sensitive to medial vibrations which could only affect a receptive agency of a definite reciprocity?

Until we can explain and show the frct of intermaterial communication there must, of course, be ridicule of those suppositions, and that persun remains in possession of the field of human intelligence who loudly proclaims as his creed, "I believe just what I can see, hear, feel, or smell, and nothing more."

When I say to another person, "You will sleep tomorrow at 10 a.m," I arouse his expectant attention I arouse a process which goes on in certain cells ; I arouse a process akin to my own, which, through intensification, becomes in my subject a dominant and reinforced idea, to the exclusion of others. When I say to a person, "You cannot get off that chair," and when the person finds that he cannot, what has happened? I arouse in him a definite idea, and the vibrations are in harmony with mine, the new idea is reinforced and becomes dominant, and therefore imperative; for, surely, to have the idea that I cannot get off a chair means the actual inhibition of the idea that I can do it, and so there is nothing to set in action the muscles necessary for getting up.

In the same way the command to go to sleep involves the arousing of a dominant idea, the muscular expression of which is the closing of the eyes, the adoption of a reclining attitude, and the assumption of the prodromata of sleep.

It is common knowledge that the strenuous tension of the idea is so essentially the antecedent of muscular action that it is often impossible to control the latter in the presence of the former, hence the term "ideo-motor action," and generally we may sum up the action of the person who is obedient to suggestion or to hypnotism in the words "ideo-motor"; but this form of action is of the impulsive kind, of what Wundt calls simple voluntary action, and the chief constituent of it is Feeling-we all know that the more emotional a person is the more impulsive, the more liable to suggestion he is. The art of the suggestor, or of the hynoptist, is the creation of a state of mono ideism, of reduction to a condition in which the balance of motives is upset and where there can be no choice, and this is done by the influence of personality, by authoritative or persuasive tone of voice, by the means of artificial aids, such as electricity, crystal-gazing, etc, which tend to concentrate the attention upon what is being said, to arouse an idea of the same tone as the suggestor's, reinforced in harmony with it. External voluntary action cannot exist without an internal process, though the converse does not hold. The suggestor knows that the assumption of an external position may, however, lead to the internal idea of which it is the expression, and he almost invariably (anyhow at first), imposes certain muscular adjustments, knowing that his best way to influence and set up definite internal conditions is by what has been termed the muscular element of thought. Can internal voluntary action be registered by any meansthat is, Can thought be made manifest, apart from some muscular demonstration?

Here lies the great secret. If it can, then telepathy is possible. Can the mere internal willing something cause the thing willed to come to pass? You will probably say, "No; because if it could there would be an end of individualism and of secrecy. If by merely willing I can compel another to disgorge the contents of his internal nervous action, there is an end of speculation, of deceit, of bargaining - any person's mind would be open to the caprice of another, and the word 'privacy' would cease to have an intelligible meaning!"

It is true that we can sometimes tell what is going on in another person's mind, but only when he gives the clue by involuntary muscular action, as by a cry or a start, or by an involuntary blushing or pallor-only by some medium of external communication of this sort.

A strong internal concentration is a personal proprium, a self-determinant, only capable of influencing others by example or the spoken word. At times so strong as to assert itself, it displays what is going on by an involuntary exclamation or movement, but, if combined with this internal thinking, there is sufficient inhibition, then no one can divine what is going on. Those who profess to be thought-readers are really persons of quick perception trained by experience, who are thereby able to notice minute physical changes in expression, colouring, or action, and to draw conclusions which are not manifest to others less gifted or accomplished in the art of interpretation.

Look away from man for a moment.

Is there going on outside us a world of Force which requires for its display the human mechanism? If there is Force existing under these conditions, does it ever show itself in apparently purposeless actions? For example, How is it that there have to be stimulations of the human mechanism in a way which is palpable before we agree to notice brain or nerve action? A person may be sitting quietly, when all at once he says or does something unexpected by himsell or others. He may even say, "I wonder what made me say-or do-that. It seemed suddenly to occur to me, for I vras not thinking of it at the time." Such instances must be viewed with great suspicion, for as a rule it is possible to trace antecedents to both internal and external action-as a rale, I say; but if our first premiss is true-namely, that there may be external Forces at work which are able to affect the human mechanism - it is surely not possible to deny that the individual may have been moved to speak in a way unknown to himself by some influence of which he was the appropriate medium. There must be-there arepaths of subconsciousness leading to the connexion between ideas which it is difficult, perhaps not possible, to trace, owing to their rapidity or to their low intensity. For instance, two men may be faced with the same mathematical problem; the one without any hesitation gives the correct answer (which is indeed a judgement process differing in quantity from the first proposition, and only possible in its solution by a continuous chain, how. ever rapidly the links may be traced over), whilst the other arrives at the same conclusion by a slow process the steps of which he is painfully conscious of; but if asked to state how he arrived so rapidly at his judgement the born mathematician will say that he cannot tell you-the result seemed to come at once without any consciousness of intervening processes, though, of course, these must have occurred, but they were too rapid and feeble to rise into a perception of them.

It is, then, hypothecating the predicate to assume that there is no connexion between ideas because we are not able to trace it at all times. Many will recall occasions when, though not at first able to trace the steps by which the connexion between ideas occurred, they were yet able by diligent attention to so intensify the intervening steps that they finally rose into consciousness and clearly demonstrated that the association between ideas was actually a determined one.

To prove that the perception of sensation demands a definite intensity and time in the receptor, it is only neces. sary to mention that it is possible to read so quickly that only a blurred consciousness follows of what has been read-there was no time for the too rapid outer impres. sions to rise to a full consciousness of their meaning.

Remember that our present question is that of the possibility of external Force influencing the human organism. Can these abstract "mental atmospheres" affect the nervous system so that an insanity, or a group of symptoms, may be set up without a morbid internal physical alteration? Can we suppose that sudden and temporary frenzies may be produced in this way, just as if, considering the human mechanism by itself, there was a wild and tumultuous agitation or sweeping over of the instrument in such a way as to cause a discord or incoherence? Such a condition would be a true functional insanity, and would account for those cases in which, though mixed up with incoherence and even delirious and strange actions, there is yet evidence of intelligence and 
perfect sanity in the conduction of the ordinary affairs of life, and after death there are no more traces of disease than may be found in any one whose mental action has been ponsidered normal.

If the body, and brain are just merely instruments for the working of this Force, then our actions denote that some changes are going on in the nature of this Force for which there is in us no responsibility. Wo are just puppets, as it were, the keyboard of an electric installa. tion. And, if so, man is just a necessary complement of this Force, nothing more, and the object of his creation was merely that of a Force terminal, an Eolian harp which discloses the motion of winds which we cannot see. If the existence of the Force we are discussing is a chimera, a fantastical creation, what are we to say to the writings of the Prophets in the Old Testament? They wrote things which they did not understand and had no knowledge of at the bidding of a Voice, and some of these fore. bodings actually came to pass. Was this just a coincidence? How could they write what seems to us wonderful, not having before any experiences which could make possible the things about which they were writing ? We must either disbelieve the Old Testament or confess to the existence of a Force which we do not understand, and have not, up to the present, been able to demonstrate.

But we recognize that a man may be so placed that his bodily conditions set up manifestations of mind, so that a reverse process is set up, and Force is, in its turn, compelled ; for example, a man is placed in uncomfortable, or even dangerous, conditions : he sets to work to extricate himself by the exercise of an internal mental process and by, external organs, and this has just the same effect as a guiding external process. There. is no efficacy in Prayer unless we believe that an external Force can be brought to bear on our internal mechanism. Whatever is the virtue of the agencies at work outside us the, key that unlocks their, manifestation in ourselves, is .Sensation-no Sensation, no mind-not no nervous action, but no mindperbaps we may say that sensation is the earliest form of mind, and. who shall say how impalpable may be the causes of Sensation, or what is their true nature?

Take the instance of the oak-eggar moth, whose power of attraction has been brought to my notice by Dr. Ernest Carter. If the female insect is put in a box covered by gauze the male insects are attracted from an enormous distance. This is probably due to a very refined sensory power, but no one knows for certain that it is so, and even if it is the instance just shows how potent are the agencies going on around us of which we know nothing.

What is body without mind? What is mind without body? The former can illustrate some forms of organic life, but that is all ; the latter may exist, in some form or other, but we cannot prove it, and this proof is just what we are most anxious to obtain. We want to know the nature of the Force which when interpreted through the human mechanism means mind. That there is some such energy we must believe, because we witness results which can only be conceived as occurring from the action of an external agent. The people who deny this external agency say: "Prove it to us; describe its nature and reactions, and we will believe it. We are quite satisfied with things as they are, and we do not require an external force to explain them." The others say: "Such and such mental manifestations have occurred, and can only be accounted for by external Force which has been made manifest in persons of particular composition and susceptibility; there is no trickery about it, and you cannot prove any doceit.", And so, apparently, the matter rests.

It is Life which links up mind and body, but Life is not mind; there is plenty of Life without mind, but there is no mind, as we know it, without Life. Are Life and Spirit the same thing? A living body is evidently a combination of body and something else. What is that "else"? A dead body cannot be revived by mere mechanical agency. A living body has selective powers; it incorporates this and it rejects that; and this selective power is its Life. When the selective powers cease the organ is dead. Nutrition, or selective power, is Life, but it is not of necessity Mind. In sleep there is selective power; the nutrition of the nervous system goes on; but that is not Mind, because manifestations of Mind are absent unless when shown by the accidental occurrence of dreams. So that Life is not Mind, for will: attention; feeling, and every other mental function may be in abeyance, but there is still Life in the parts.

Why is it necessary to think that there is such a thing as external or spiritual mind?. Why will it not do to confine our speculation to the live body? It is clear that there is something besides the body; there is the live body, and we have shown that Mind and Life are not the same thing. There is a certain school of thinkers who do so confine themselves; for them the living body is enough. They, argue that it does contain in itself all the elements for voluntary action, ideation, etc., without the necessity of invoking any other agent. It is sufficient for them that the body is alive, and they are not concerned with what it is that makes it alive. Given this, they profess to be able to explain the action of the processes by the essential constitution of the body itself. The people who hold these views are competent investigators, who have persuaded themselves that, they are sufficiently satisfied with things as they are. I do not know that they are opposed to the possibility of such a state as hypnosis, nor to the agency of such a thing as Suggestion, because it is to every one patent that hypnosis and Suggestion are everyday facts, but they explain them in their own way-by the terms of the organization itself-and they deny that it is necessary to call in any Force or Power of which we know nothing. It may be permitted to ask, however, if, they really are satisfied, or whether it is not that they take things as they are and assume that the mechanism is perfect and self. sufficient? Their explanation of Hyppotism is that the condition depends upon the acquiescence of the living bod itself, that it is not due to any force or special essence in the hypnotizer, but that it is purely a subjective state-is, in fact, an auto-process; and, as to Suggestion, they aver that it is merely the acceptance of an idea which is made. strong or reinforced by repetition, and which thus becomes a belief, and therefore sets up an action of the kind desired by the suggestor. And who shall gainsay them? If it ever comes to be proved by physical methods that influence can irradiate from one body to another, that there are conditions of matter which can affect some organisms and not others, then, no doubt, they will give their assent to the demonstration ; but, as things are, they refuse their belief to the statements of clairvoyants and telepathists, because only certain results are, affirmed, and neither, agent nor process can be analysed nor made patent.

- Whilst this is the condition of some psychologists, there are yet many others who are not satisfied, with regarding the body as self-contained. It does not content them to. assert that there is no guiding power to our actions and thoughts as they are willed; it does not satisfy them to reject the affirmations of others because they do not come within their own category and cannot as yet be explained they quote their feeling that there is yet something behind these occult manifestations, and they point to the truth that many things which at one time were not believed but were said, indeed, to be impossible, have become now accepted commonplaces.

There is really no reason for thinking that we have such a thing as an "activity process." Why can we not be satisfied with a Life or a Force which, when attached to an organism, sets up certain processes? For, after all, there is such a thing as Life, and it is superior to mind and body, making them but its complements. Life can surely go on without mind and body, but the latter are useless without the former. At any rate, there is some. thing which, when joined to the body, means mind and actions, and which, when abstracted, means death or cessation of function. Whether this something is Life, or whether the term "Life" must be kept for the Forcethe something, as shown by its union with an organic body-is perhaps a question. It cannot make stone into bread ; it cannot, having once left an organism, re-enter it, revivify it, as it was before. It must have been with it from the first. It is a thing by itself, and we. know nothing of its nature when separated from the body. It is not electricity, nor magnetism ; these are but manifesta. tions of it in other ways. It requires a definite kind and state of material for its association; it cannot work through injured material, because we see that under certain condi tions of injury or disease it forsakes its complement and the material degenerates into lower forms of matter, upon which this "Life" has no influence. Whatever its nature it must be differently modified according to the nature of 
the medium ; and as no two bodies are the same, it follows that their living manifestations must be different, though the more closely two bodies approach one another in com. position the more similar must they be in vital manifestations; hence we may conceive the possibility of what have been called "affinities"-conditions in which two persons seem to be in some sort of relationship which is inappre. ciable by others. Physical alterations, such as food, education, etc., set up alterations in tissue, and therefore vital Force is constantly having changing material to work upon, which will cause manifestations which we can neither expect nor explain, baulking anticipations of uniformity of action and giving occasion for surprise at what happens.

Vitalized material must have radiating external influence, and moving Life (a body in action) will possibly have influence on a similarly attuned moving Life. How we are to show this is the question. Falling in love, apart from the more sexual question, is a subject worthy of more scientific treatment than is generally accorded to it. That people of the most apparently diverse personal attributes and social positions should be so attracted to one another as to fly in the face of family prejudices, and that they can give no reason for the attraction save the feeling that it exists, is beyond explanation. It is possible that the attraction which sometimes is found-and which is looked upon generally with reproach by society-between persons of the same sex, is founded on deeper structural affinity than we are willing to recognize. The Schwärmerei of the Germans, the "Urnings" of this country, refer to con. ditions which most people are unable to understand, but apparently they are conditions well recognized by many who act upon the compelling force of their attaction. It seems as if something in the one person met with its complement or reinforcement in the other (vaguely described as "animal magnetism"). Such persons are thought to be abnormal, or even degenerate, and yet they may be people of great intellectual power; but society, not understanding, refuses to condone such alliances. Perhaps from our standpoint we may take a more reason. able view of these eccentricities, and be content to allow a possible cause for what we cannot explain, though we refuse to consider as a depravity. All this points to the conclusion that there is something in us, and of us, and round about us, of which we know nothing.

Hypnotism need, then, not mean any peculiar power in the hypnotizer; it is a subjective state brought on by reduction to a state of mono-ideism through the insistence by an outsider that such and such a condition will occur this idea continually reinforced becomes a positive compelling idea, and as such must act in its own way, and will set up its own associations. Any one, then, can hypnotize; it requires no special auto-force beyond a certain amount of definite assertion and a little art; the real agent is the hypnotized himself, and if he resolves not to submit to the ideas suggested to him, there is no reason why he should be hypnotized at all, unless, indeed, certain physical processes have been used to bring on fatigue, in which case he may lose his power of inhibition, and thus drop into the train of thought proposed to him. Suggestion is very much the same thing. There is no mystery about it. It is the setting up or prompting an idea which by constant reinforcement is turned into a dominant one leading to action in its own direction. It is just a matter of education, and can be undertaken by any one, but more success. fully, of course, by those who are said to be authorities on the subject, and to whom people turn with a mental state already predisposed in favour of the suggestor.

The case of telepathy is different. No one is competent to assert that it exists; no one can deny the possibility of it; we are in the hands of the physicists; we have arrived at the conclusion that manifestations of mind do not depend upon the body alone; the material through which these manifestations occur is there, but without that something which we have called Life it cannot be envisaged. We must suppose that when the living body dies there must be an upset in this external Life or Force, just as there is when one is born, so that there must be constant change going on in this Force, which when in union with the body means the living body, and calls forth its manifestations, of which Mind is only one. When Life leaves a body we must suppose that it may have been modified by its connexion with that body; we can scarcely con. ceive that it is altogether unaffected, but rather that it has a definite form still capable of affecting an organism of a receptive or complementary character. Take for a moment those cases where persons allege that an image of a friend or relative has appeared to them at the moment (as afterwards ascertained) of his death. It might be seriously argued that the Force or Life which at the moment of rupture left the body was so modifiea that for a time, at any rate, it was able to so act on another similarly tuned bodily organism as to re-excite correlated parts in it. Of course, most of the so-called ghosts or apparitions are subjective intensities projected externally in people who are placed in circumstances prepared for the realization of what has been discussed and is expected. If a person of strong power of attention goes to see the Hampton Court ghost appear at a certain given time and garbed in a certain manner he will probably see it. That is a case of subjective ideal projection, but such a case is very different from the one described in my book, $E x$ cathedrâ Essays (p. 137), where all knowledge of what had previously happened was ex post facto. It may be quite correctly urged that this is a theory made up to explain occurrences, and that if it were true we should have more frequent demonstrations of its action-for example, it might be expected that at the time of the death of a murdered person there might be the presentment of it to some other living friend, but I have never heard of this, nor can I explain why it should not happen, if the other instances cited are true.

There can be no scientific hypothesis in favour of fortune-tellers or seers into the future, or in the host of crystal-gazers who profess to foretell what is going to happen. All these are but people who form more or less shrewd judgements from what they have heard or have noticed, and who combine it with strongly asserted guess-work. Such prophecies are essentially of the nature of suggestion, and their object is to arouse a strong sub. jectivity, which may by chance eventuate in action of the desired kind.

In the year 1904 I wrote in the same strain as I am now doing. Since that time I cannot find out that our knowledge has been materially increased. The cry is still the same: "Show us proofs of an activity-process; prove to us the nature of the Force which, acting through organic material, makes it a living thing." True we have acquired knowledge of radio-activity, and we have had theories of a coloured bodily aura, but we want to have it shown whether the living body irradiates in any way. When the Force which we call the Life ceases to act on the body, is it in any way altered so that it can still, to some degree, affect other living matter? Can living matter affect other living matter at a distance by means of a change in the medium between the two, apart from the agency of known conductors? Surely it can-it must. A magnet lies quietly on the table, but we know that there is a modified medium within a certain distance, because we find that within the limits of its agency a piece of metal flies to it. But, beyond the fact that the metal flies to it, we should not. know that there was any existing alteration of the space between them. We want more knowledge of the invisible and the intangible before we can refuse to believe the trath of what we often see or hear, but which is called deception. Meantime, we wait in the hope and in the belief that some of the nature of the multitudinous processes which are going on outside our ken are jet within the field of demonstration to such powers as we have or shall attain to.

What a field for speculation it is to consider the number of forces which are going on outside us of which we have no knowledge, though some of them must affect us in different ways, and may be at the root of our obscure feelings, ideas, and actions. Meanwhile, we go on patiently toiling - not forgetting, however, that there probably are processes going on which we may never be able to demon. strate; they are in no relationship with us, and pass us by without notice; being of a different order, we are as nothing to them, and they are nothing to us.

It is quite right to form hypotheses on these subjects; indeed, the whole chapter of J. S. Mill on "Hypotheses" should be studied, for nearly everything which is now theory was once hypothesis. There is no reason for assuming that the true explanation must be one which with only our present experience we could imagine. Among the natural agents with which we are acquainted 
the vibrations of an elastic fluid may be the only one whose laws bear a close resemblance to those of light; but we cannot tell that there does not exist an unknown cause other than an elastic ether diffused through space, yet producing effects identical in some respects with those which would result from the undulations of such an ether.

And so we go on from hypothesis to theory, from theory to an actual knowledge of the facts and their causes -some day.

\section{ABSTRACT OF A LECTURE ON PSYCHO- PNEUMATOLOGY;}

OR, THE INTERACTIONS OF MIND, BODY, AND SOUL.

Delivered as an Introduction to the Summer Course OF LECTURES,

BY JAMES RORIE, M.D.,

LEOTURER ON MENTAL DISEASE, UNIVERSITY COLLEGE, DUNDEE.

Is a review of "Philosophy by Experience (Pragmatism)," by $\mathrm{H}$. Heath Baden, in a recent issue of Nature, the fol. lowing occurs: "The only futare that is possible is an immortality of function. An organism is nothing but a centre or focus through which the world energy operates. When the organism is lost in what we call death, the function may well enough go on in terms of more subtle forms of energetic activity. Perhaps if a criticism may be ventured, modern ' Psychology-without-a-Soul ' has become too much afraid of being metaphysical-a function must be a function of something. If there is an act there must be an Actor, who is in a way greater and more real than the Act. A Soul entity, then, is justified. It is as reasonable to posit it as to posit a surviving function." Sir Francis Galton, in a letter to the Times of May 31st, writes: "The march of science is fast obliterating the distinction between the material and the non-material, for it is now generally agreed that matter is a microcosm of innumerable and it may be immaterial motes, and that the apparent vacancy of space is a plenum of ether that vibrates throughout like a solid."

Statements such as these (and many others might be quoted) show that the reaction, which was bound sooner or later to come about, against the materialistic monism introduced by Carl Vogt half a century ago, has now fairly set in, and that while physiological and experimental psychology have led to no small advances in neurology, they have done very little towards increasing our knowledge of pure psychology or the real nature of mental activity. They only male it clear that, if we are to arrive at a correct analysis of man's mental constitution, the spiritual element cannot be set aside and disregarded.

As this subject is now attracting considerable attention, the following (which is practically the terminal portion of my introductory lecture on mental diseases, recently delivered in Dundee University College) may interest some readers.

At the present time there are no questions of greater importance or more pressing for solution than those con nected with the nature of the physical and cerebro-neural changes underlying the mental state, as revealed in consciousness. The most recent discoveries made in the general and microscopic anatomy of the brain, and the views now entertained as to the nature and physiological importance of the neuron and nerve cell, or "psychical organic unit"; the important fanctions discharged by the neuroglia, formerly looked upon merely as a connective tissue, but now found to be an antitoxic protective agent against brain-blood poisoning, and also regulating the chemical process of nerve tissue metabolism, all show an immense advance in neurology. A great change has also taken place in our ideas in regard to mental activity, in so far that what formerly was treated of as mental philosophy is now studied as physiological psychology, and many phenomena regarded formerly as purely mental are now, under the title of "psyoho-physics," subjected to rigid experimental investigation in laboratories specially fitted for the purpose. Again, instead of viewing the mind as operating through certain faculties peculiar to it and apart from the body, psychologists now begin at the other end, working gradually up from the stimuli or physical forces operating on the nerve end organs, specially provided for the conversion of these--such as the vibrations of the atmosphere in the case of hearing, and those of the ether in regard to vision-into the nerve current; a vito. neural energy, and its transmission as such to the cerebral nerve cells. The difficulties experienced in further tracing the transformation of nerve energy into purely psychic or mind force-that is, how mind acts on matter and how matter acts on mind-still remain, however, as great a puzzle as before to all investigators. The opinions of various eminent authorities show a pretty general agreement in the view, as expressed by Goodsir "that it would be unphilosophical, and could not. be admitted by the physicist even as a hypothesis, that a psychical power and a physical force can act and react on one another, and that the future elucidation of the problem would probably depend on the cautious philosophical investigation of their mutual influences." The weak point in this view is in assuming that a physical force does act on a psychic energy, and vice versa. Recent discoveries in physical science rather indicate that through the influence of the nerve end organs the atmospheric and ethereal vibrations-purely physical energies-are transformed into a vital nerve force with totally different properties, although itself as yet of unknown nature, and that it would not be assuming too much to imagine that through an analogous process in the cells of the cerebral cortex the nerve current passes into the condition of psychic energy.

But here again another difficulty presents itself, for although the above might go far to explain the phenomens of the primary activities of such intellectual processes as sensation, perception, association of ideas, etc., it would not explain those of consciousness, freewill, and memory, to say nothing of conscience, morality, and religiosity. For the manifestation and recognition of these a higher form of energy seems imperative; it is just here that the materialistic monism which was introduced into this country by Carl Vogt and other German writers fifty years ago, and has during these years exercised so great a control over modern psychology, breaks down. The failure there can be little doubt is due to the refusel on the part of most modern psychologists to accept any evidence except that demonstrable to the senses; they thus exclude such testimony as that of personal witnesses and under this head there must be included revealed truth. This is all the more remarkable, as such evidence was, not so very long ago, readily received by many eminent men. Michael Faraday, who spent his lifetime in the forefront of experimental research, declared in a lecture on education, delivered in the Royal Institution, London, that, "High as man is placed above the creatures around him, there is a higher and more exalted position within his view; and the ways are infinite in which he occupies his thoughts about the fears or expectations of a future life. I believe the truth of that future cannot be brought to his know. ledge by any exertion of his mental powers, however exalted they may be; that it is made known to him by other teaching than his own, and is received through simple belief of the testimony given."

But the clearest exponent of this view of man's organization was the late John Goodsir, Professor of Anatomy in the University of Edinburgh. Goodsir was not only a naturalist, physiologist and anatomist of European reputation, but also a philosophical psychologist of the first rank. He taught, that "Man in his constitution consists of three elements-a corporeal, a psychical, and a spiritual"; and these he treated as of the Sarx, Psyche, and Pneuma; that it was in the last of these, and not in his corporeal element, that his personality resided, and in the possession of which he differed so greatly from all lower animals that he ought not to be classified with them. Although Goodsir never directly said so in his lectures, there is little doubt that in this division he was influenced by the revealed declaration that man in his creation had superadded to his animal organism "the breath of life," or, as some translate it, "the breath of lives" (attributes of the Divine Three), and so became a living soul. $\mathrm{He}$ accordingly held that, "while there can be no question as to the existence in the animal of a principle allied to our own human consciousness, every unbiassed observer who has studied the actions of the various forms of animals from the protozoon upwards must feel impressed 